\title{
USE OF WIDAL TEST IN DIAGNOSIS OF TYPHOID FEVER IN NORTH INDIAN POPULATION BY ESTIMATING BASELINE TITER IN CONTROL GROUP
}

\author{
SHETTY JEEVAN* \\ Department of Microbiology, G.S Medical College and Hospital (Chaudhary Charan Singh University), Pilkhuwa, Uttar Pradesh, India. \\ Email: drjeesh@gmail.com
}

Received: 30 March 2017, Revised and Accepted: 13 April 2017

\section{ABSTRACT}

Objective: This study was undertaken to establish a cutoff significant titer for Widal test using healthy volunteers as control group. Utilizing the baseline titer obtained from the control group, a diagnosis of typhoid fever was made in the test group comprising outpatients and inpatients

Methods: Blood samples were collected from healthy volunteers and patients attending G.S Medical College and Hospital, Pilkhuwa, over a period of 6 months from September 2016 to March 2017. Antibodies to Salmonella typhi (TO, TH) and Paratyphi A (AH) and Paratyphi B (BH) are determined by this tube agglutination test. A total of 124 healthy controls and 303 patients having clinical suspicion of typhoid fever were subjected to Widal test.

Results: In healthy control group, titer TO $\geq 20$ was observed in $43(34.7 \%)$, TO $\geq 40$ in 48 (38.7\%), T0 $\geq 80$ in 25 (20.2\%), and titer T0 $\geq 160$, T0 $\geq 320$ was observed in none of the control group. Titer $\mathrm{TH} \geq 40$ in 58 (46.8\%), AH $\geq 40$ in 7 (5.6\%), and $\mathrm{BH} \geq 40$ in 13 (10.5\%) were observed in the control group. Among the test group, 96 (31.7\%) sera were positive out of 303 clinically suspected enteric fever by the Widal test. Among different age group studied, 34 (46.6\%) patients belonged to the age group of 11-20 years which formed the highest followed by the age group of $21-30$ years (33.3\%).

Conclusion: Based on the study, a cutoff titer of $\geq 160$ for anti- 0 and anti-H antibodies and titer of $\geq 80$ for anti-AH and anti-BH antibodies be considered as significant titer in diagnosis of enteric fever in this region. The baseline titer helps in early recognition and treatment of this serious health problem.

Keywords: Titer, Widal, Antibodies, Typhoid fever, Agglutination.

(C) 2017 The Authors. Published by Innovare Academic Sciences Pvt Ltd. This is an open access article under the CC BY license (http://creativecommons. org/licenses/by/4. 0/) DOI: http://dx.doi.org/10.22159/ajpcr.2017.v10i7.18789

\section{INTRODUCTION}

Enteric fever is endemic in the Indian subcontinent, and populationbased surveillance studies in selected regions add considerably in estimating the global burden of enteric fever. The incidence rate of typhoid is more than 100 cases per 100000 people per year [1]. Enteric fever caused by Salmonella typhi is called as typhoid fever and Salmonella paratyphi causes the paratyphoid fever. Typhoid is characterized by malaise, fever, abdominal discomfort, relative bradycardia, transient rash, and organomegaly and may end up in complications such as intestinal perforation, hemorrhage, and perinephric abscess $[2,3]$. Human beings are the only known reservoir host for typhoid fever, and infected person or carrier transmits the organism in his feces. Ingestion of food or water contaminated by such feces is the source of infection [4]. Drug resistance has been posing major problems in the treatment of typhoid fever and continues to be a serious problem for public health authorities [5]. Studies are being carried out to use plant constituents as potential antimicrobial agents in future for treatment [6]. Newer vaccines are being developed to overcome poor immunogenicity of some available vaccines, and research work on better adjuvant delivery systems is being carried out [7].

The definitive diagnosis of enteric fever is by culture of blood, stool, urine, and intestinal secretions. However, in many countries, where injudicious use of antibiotics and inadequate culture facilities is common, Widal test is still the most convenient way for serological diagnosis of typhoid fever. Moreover, for effective diagnosis of typhoid fever, baseline titer of the population has to be assessed.

Widal test is a classical tube agglutination test which measures agglutinating antibodies against lipopolysaccharide 0 and protein flagellar $\mathrm{H}$ antigens of Salmonella. The diagnosis relies on demonstrating rising antibody titer in paired samples 10-14 days apart. However, this rise is not demonstrable even in blood culture-confirmed cases so prompting baseline titer estimation of population a necessity [8].

There are no studies about the baseline titer been estimated earlier in this region. In studies done previously in other parts of the country, the antibody titer was found to be unusually high though it can vary from region to region [9]. In the background of such reports, it is necessary to perform baseline titer in healthy control group before conducting the test on patient sera.

\section{METHODS}

The study was conducted in the Department of Microbiology, G.S Medical College and Hospital, which is a tertiary care hospital with 350 beds situated in Pilkhuwa, Uttar Pradesh, for 6 months from September 2016 to March 2017. Consent and the approval of the Institutional Ethical Committee was obtained for carrying out this study. People with underlying respiratory infections, malaria, dengue, hepatitis, hematological, or other systemic disorders were excluded from the study.

\section{Control group}

The control group consisted of 124 healthy people who are free of signs and symptoms and not having significant ill health within the past 2 months or typhoid fever in the past 6 months. Those who gave history of vaccination in the preceding 3 years were excluded from the study. Among the control group, male constituted $41.13 \%$ and female $58.87 \%$ from age group of 1 to 65 years.

\section{Test group}

The test population consisted of 303 clinically suspected typhoid fever cases attending the hospital as outpatients (O.P) or admitted as inpatients (I.P). Patients previously treated with antibiotics such as 
Table 1: Antibodies titer against Salmonella antigens in the control group $(\mathrm{N}=124)$

\begin{tabular}{|c|c|c|c|c|c|c|}
\hline Antibody titer & N (\%) & $\geq 20 \mathrm{~N}(\%)$ & $\geq 40 \mathrm{~N}(\%)$ & $\geq 80 \mathrm{~N}(\%)$ & $\geq 160 \mathrm{~N}(\%)$ & $\geq 320$ N (\%) \\
\hline S typhi 0 & $116(93.5)$ & $43(34.7)$ & 48 (38.7) & $25(20.2)$ & $0(0)$ & $0(0)$ \\
\hline S typhi $\mathrm{H}$ & $108(87.1)$ & $39(31.5)$ & $58(46.8)$ & $11(8.9)$ & $0(0)$ & $0(0)$ \\
\hline$S$ paratyphi AH & $08(6.5)$ & $01(0.8)$ & $07(5.6)$ & $00(0)$ & $0(0)$ & $0(0)$ \\
\hline S paratyphi BH & 19 (15.3) & $06(4.8)$ & $13(10.5)$ & $00(0)$ & $0(0)$ & $0(0)$ \\
\hline
\end{tabular}

$\mathrm{N}$ : Total number of positive sera in the control group, $\mathrm{N}$ : Number of positive sera against different antibody titer

chloramphenicol or had recent typhoid illness or having chronic active liver disease were excluded from the study. Significant titer determined from control group was applied to make a clinical diagnosis of enteric fever.

A volume of 3-5 $\mathrm{ml}$ of venous blood was collected into a sterile test tube and centrifuged for 5 minutes to separate the serum from blood. Commercially available antigen containing Salmonella enterica serovar Typhi $\mathrm{O}$ and $\mathrm{H}$ antigens and Paratyphi $\mathrm{AH}$ and $\mathrm{BH}$ antigen were used (Arkray Healthcare Pvt., Ltd.,Surat, India).The test used two-fold serially diluted sera of control and test group, dilution being from 1:20 to 1:320. All serum samples were first diluted in a 1:20 ratio with isotonic normal saline in such a way that the final volume amounts to $1 \mathrm{ml}$. Dilutions of $1: 40,1: 80,1: 160$, and 1:320 each were made serially in 4 rows. Add a drop of the appropriate antigen to all the corresponding tubes in each row. A known positive control, negative control, and antigen control were also set up in each row. All the tubes are mixed well and incubated at $37^{\circ} \mathrm{C}$ for $16-20 \mathrm{hrs}$ and examined for agglutination. The antibody titer is the highest dilution of serum showing distinct agglutination. The 0 somatic antigen being the somatic antigen gives compact, granular agglutination whereas $\mathrm{H}$ antigen, a flagellar antigen, gives large loose fluffy agglutination.

Data were entered and analyzed using SPSS (Statistical Package for Social Science) program version 24, and statistical significance was considered when $\mathrm{p}$ value was less than 0.05 .

\section{RESULTS}

A total of 124 healthy controls and 303 patients having clinical suspicion of typhoid fever were subjected to Widal test. In healthy control group, titer T0 $\geq 20$ was observed in $43(34.7 \%)$, T0 $\geq 40$ in $48(38.7 \%)$, T0 $\geq 80$ in $25(20.2 \%)$, and titer TO $\geq 160, \mathrm{TO} \geq 320$ was observed in none of the control group. Titer $\mathrm{TH} \geq 40$ in $46.8 \%, \mathrm{AH} \geq 40$ in $5.6 \%$, and $\mathrm{BH} \geq 40$ in $10.5 \%$ were observed in the control group. Out of the 124 sera tested, only 8 sera (6.5\%) and 19 sera (15.3\%) showed positive agglutination titer for $S$. paratyphi $\mathrm{AH}$ and $\mathrm{BH}$ antibodies, respectively. Male constituted $41.13 \%$ (52 out of 124) of the control group.

Among the test group, $96(31.7 \%)$ were positive by Widal test and $34(46.6 \%)$ patients belonged to the age group of $11-20$ years which formed the highest group whereas age group $<10$ years constituted the least (20.3\%). Male constituted $50.49 \%$ and female $49.50 \%$ and O.P accounted for $58.74 \%$ and I.P accounted for $41.25 \%$ in the test group (Tables 1-3).

The present study has found the paratyphi BH titer $\geq 40$ which is found to be higher than other studies done on healthy volunteers (Table 4).

\section{DISCUSSION}

The baseline titer in Widal test among control group for TO, TH antibodies was found to be $\geq 80$ and $\mathrm{AH}$ and $\mathrm{BH}$ to be $\geq 40$ each. The high titers noticed against the salmonella antigens in the study may be due to the exposure to the cross-reacting organisms in the region. Based on this, the significant titer was determined as a cutoff titer of $\geq 160$ for anti- 0 and anti- $\mathrm{H}$ antibodies and titer of $\geq 80$ for anti-AH and anti-BH antibodies to make a diagnosis of enteric fever [9]. A study done in determining baseline titer in Garhwal region of Uttarakhand has recommended the baseline titer of $\geq 40$ for TO antibodies and
Table 2: Prevalence of typhoid fever in test group after estimating baseline titer

\begin{tabular}{lllllll}
\hline Age group (years) & $\mathbf{N}$ & $\mathbf{M}$ & $\mathbf{F}$ & $\mathbf{0 . P}$ & $\mathbf{I . P}$ & $\mathbf{N}(\%)$ \\
\hline$<10$ & 59 & 31 & 28 & 34 & 25 & $12(20.3)$ \\
$11-20$ & 73 & 40 & 33 & 35 & 38 & $34(46.6)$ \\
$21-30$ & 60 & 31 & 29 & 41 & 19 & $20(33.3)$ \\
$31-40$ & 46 & 21 & 25 & 29 & 17 & $14(30.4)$ \\
$41-50$ & 30 & 08 & 22 & 20 & 10 & $08(26.7)$ \\
$>50$ & 35 & 22 & 13 & 19 & 16 & $08(22.9)$ \\
Total & 303 & 153 & 150 & 178 & 125 & $96(31.7)$ \\
\hline
\end{tabular}

$\mathrm{N}$ : Total number of patients examined in different age groups ( $\mathrm{N}=303)$, M: Male, F: Female, O.P: Outpatient, I.P: Inpatient, N: Number of patients positive by Widal test by utilizing baseline titer

$\geq 80$ for $\mathrm{TH}$ antibodies. Positive agglutinins for paratyphi $\mathrm{AH}$ and $\mathrm{BH}$ were found in only $3.04 \%$ and $1.3 \%$, respectively. In this study, 8 sera $(6.5 \%)$ and 19 sera (15.3\%) showed positive agglutination titer for $\mathrm{AH}$ and $\mathrm{BH}$ antibodies. The baseline titer for paratyphi $\mathrm{AH}$ and $\mathrm{BH}$ groups was found to be $\geq 20$ each in their study [10]. Similar baseline titer was also noticed in Thiruvananthapuram in South Kerala [11]. The baseline titer determined was 40 for anti- 0 and anti- $\mathrm{H}$ antibodies and $<20$ for anti-AH and anti-BH antibodies in another study done in North Kerala where public health facilities and hygienic conditions are better [12]. Another study done in Raichur recommended TO and TH titer of $\geq 320$ as diagnostic of typhoid fever, and for $\mathrm{AH}$ and $\mathrm{BH}$ titers, it is $\geq 40$ and $\geq 160$, respectively [13]. Baseline Widal titer study done in rural Pondicherry recommended $\geq 160$ for 0 and $\mathrm{H}$ agglutinins while for $\mathrm{AH}$ to be $\geq 80$ and $\mathrm{BH}$ to be $\geq 40$ to be considered a significant titer in diagnosing typhoid [14]. A study done in Dehradun on apparently healthy population found agglutination titer for $\mathrm{TO} \geq 20$ in $28 \%$, $\mathrm{TO} \geq 40$ in $24.6 \%$, TO $\geq 80$ in $10.3 \%$, $\mathrm{TH} \geq 80$ in $7.6 \%$, $\mathrm{AH} \geq 20$ in $6.6 \%$, and $\mathrm{BH} \geq 20$ in $4.6 \%$ [15].

In this study, T0 antibodies (93.5\%) agglutinated more compared with TH (87.1\%), AH (6.5\%), or BH (15.3\%). Even infected patients' sera agglutinated more with somatic antigen of $S$. typhi than the flagellar antigen. These findings have been noted in several studies [16]. Furthermore, several studies highlight the increasing cases of enteric fever due to paratyphi, but this study differs from such observation. Widal test helps the physician in making a rapid diagnosis instead of relying on blood or stool culture which is time-consuming. Added to this is self-medication by the patients and injudicious prescription of antibiotics by local doctors make culture tests less reliable.

Among the patients who attended the hospital with clinical suspicion of typhoid, $31.7 \%$ showed significant titer to S. typhi antibodies and none to paratyphi. Age group of 11-20 years showed highest prevalence (46.6\%) followed by the age group of 21-30 years (33.3\%). A similar study done in Aba, Nigeria, showed $24.5 \%$ positive Widal test, and in age-related prevalence, the age bracket 31-40 years showed the highest prevalence rate by both Widal and blood culture method. Sexrelated prevalence showed that more males were affected than female population [17]. Study done in Turkey recommended agglutinin titers of $\geq 200$ having diagnostic significance and Widal test performed 7-10 days after hospitalization gave the most reliable results with high specificity, sensitivity, and positive and negative predictive value [18]. 
Table 3: Distribution of the positive cases according to the gender-age

\begin{tabular}{llllll}
\hline Sex & Number & Mean \pm SD & SEM & Chi-square & Df \\
\hline Male & 44 & $21.090 \pm 13.738$ & 2.071 & 10.045 & 28 \\
Female & 52 & $26.423 \pm 17.744$ & 2.460 & 20.500 & 0.999 \\
\hline
\end{tabular}

$\mathrm{p}<0.05$ considered significant, Df: Degree of freedom, SD: Standard deviation, SEM: Standard error mean

Table 4: Comparative analysis of baseline titer of $\mathrm{O}$ and $\mathrm{H}$ agglutinins in different parts of India

\begin{tabular}{llllllll}
\hline \multirow{2}{*}{ Author } & Place & Year & \multicolumn{2}{l}{ Titer } & & & \\
\cline { 4 - 8 } & & & TO & TH & AH & BH \\
\hline Shekar Pal et al. & Garhwal & 2013 & $\geq 40$ & $\geq 80$ & $\geq 20$ & $\geq 20$ \\
Kataria et al. & Dehradun & 2013 & $\geq 80$ & $\geq 80$ & $\geq 20$ & $\geq 20$ \\
Bijapur et al. & Kannur & 2014 & $\geq 40$ & $\geq 40$ & $<20$ & $<20$ \\
Jeyakumari et al. & Puducherry & 2015 & $\geq 80$ & $\geq 80$ & $\geq 40$ & $\geq 20$ \\
Present study & Pilkhuwa & 2017 & $\geq 80$ & $\geq 80$ & $\geq 40$ & $\geq 40$ \\
\hline
\end{tabular}

There was no statistical significance between gender and age in this study $(p>0.05)$. Similarly, no significant result was seen in another study done in Yemen, but the prevalence was highest in the age group $>20$ years. The study found that the main symptom in majority was fever followed by diarrhea and abdominal pain [19]. A study conducted in Owerri, Nigeria, has found that the typhoid fever was high among youths who consume unsafe drinking water and food from outside source which may be one of the reasons in this region too [20]. Serological tests such as Widal performed in the laboratory help in differentiating from other causes of febrile illness such as dengue [21].

Although blood culture is gold standard for diagnosis of typhoid fever, excessive antibiotic use has reduced this isolation rate. A study in Varanasi has found a significant increase in the overall seropositivity rates from 1998 to 2011. A rising prevalence of non-typhoidal salmonellae has contributed to such change. Furthermore, a fact that typhoid fever is primarily a disease of childhood and early adolescents may not hold true against a background of changing epidemiology due to childhood vaccination policies [22]. Relative frequencies and age distributions of invasive non-typhoidal salmonella and typhoid are found to be contrasting [23]. When the level of agglutinins was correlated with age in another study, it was found that the titer increased with duration of illness in adults but not in children [24].

\section{CONCLUSIONS}

Widal test still remains an important diagnostic tool since it is more convenient, reliable, cheaper and faster than culture, molecular, and other serological tests. Although new rapid serological tests are available, they need to be carefully validated before being used. However, the results of Widal test need to be analyzed based on endemicity and cross-reaction of antigen with other salmonella and non-salmonella species. Thus, it can be concluded that in hospitals, where facilities are limited, a presumptive diagnosis of typhoid fever can be comfortably made after estimating baseline titer of the region.

\section{REFERENCES}

1. Crump JA, Luby SP, Mintz ED. The global burden of typhoid fever. Bull World Health Organ 2004;82(5):346-53.

2. Pegues DA, Miller SI. Salmonellosis. In: Kasper DA, Hauser SL, Jameson JL, Fauci AS, Longo DL, Losalzo J, editors. Harrison's Principles of Internal Medicine. 19 ${ }^{\text {th }}$ ed. New York: McGraw Hill Education 2015. p. 1049-55.

3. Devi S, Bhat KS, Kanungo R, Rajan RP. Salmonella enterica var. typhi as an uncommon cause of perinephric abscess: A case report and review of literature. J Curr Res Sci Med 2015;1(1):41-3.

4. Mweu E, English M. Typhoid fever in children in Africa. Trop Med Int Health 2008;13(4):532-40.

5. Arora D, Gupta P, Gill G, Chawla R, Singla R. Changing trends in the antibiogram of Salmonella isolates in northern area of Punjab. Int J Pharm Pharm Sci 2010;2(3):135-7.

6. Soni A, Dahiya P. Screening of phytochemicals and antimicrobial potential of extracts of Vetiver zizanoides and Phragmites karka against clinical isolates. Int J Appl Pharm 2015;7(1):22-4.

7. Nirmala L, Nayak V, Raman D. Immunoevaluation of typhoid antigen by using potato starch natural biodegradable polymer as a single contact used as an adjuvant. Int JPharm Pharm Sci 2011;3(4):78-83.

8. Abutiheen AK, Altumma MA, Heniwa RA, Zahra MA, Zainab MA. Prevalence of positive widal test among healthy personnel in Kerbala. Karbala J Med 2015;2(2):2265-71.

9. Collard P, Sen R, Montefiore D. The distribution of Salmonella agglutinins in sera of healthy adults at Ibadan. J Hyg (Lond) 1959;57(4):427-34.

10. Pal S, Prakash R, Juyal D, Sharma N, Rana A, Negi S. The baseline widal titre among the healthy individuals of the hilly areas in the Garhwal region of Uttarkhand, India. J Clin Diagn Res 2013;7(3):437-40.

11. Aruni IS, Prabakaran P, Kumaran J. Study of baseline widal titre against Salmonella species among healthy individuals in Thiruvananthapuram district of Kerala, South India. Experiment 2014;20(1):1380-3.

12. Bijapur GA, Kakkeri SR, Raysa NP, Usman SM. A study to determine significant titre-values of widal test in the diagnosis of enteric fever for a population of North Kerala, India. Al Ameen J Med Sci 2014;7(1):72-7.

13. Bahadur AK, Peerapur BV. Baseline titre of widal amongst healthy blood donors in Raichur, Karnataka. J Krishna Inst Med Sci Univ 2013;2(2):30-6.

14. Jeyakumari D, Sneha AJ, Gopal R. Study of the baseline widal titres among healthy individuals of rural population in Puducherry. Int J Med Res Health Sci 2015;4(2):322-6.

15. Kataria VK, Bhai N, Mahawal BS, Roy RC. Determination of baseline widal titre among apparently healthy population in Dehradun city. IOSR J Pharm Bio Sci 2013;7(2):53-5.

16. Agbulu CO, Nkiruka CM, Yaji ME. Comparison of widal test and stool culture technique in diagnosing typhoid fever in Okpokwu local government area, Benue state, Nigeria. Acad J Microbiol Res 2016;4(1):1-4

17. Ezeigbo OR, Agomoh NG, Asuoha-Chuks N. Laboratory diagnosis of typhoid fever using widal and blood culture methods in Aba, Southeastern Nigeria. Am J Microbiol Res 2015;3(6):181-3.

18. Willke A, Ergonul O, Bayar B. Widal test in diagnosis of typhoid fever in Turkey. Clin Diagn Lab Immunol 2002;9(4):938-41.

19. Al-Ameri G, Saif N. A prevalence study of typhoid fever in Taiz and Al-Hodiedah cities in Yemen. Br Microbiol Res J 2014;4(2):214-23.

20. Ibegbulam-Njoku PN, Chijioke-Osuji CC, Duru FC. Prevalence of antibody titre in healthy individual and enteric fever patients in Owerri, Nigeria. J Public Health Epidemiol 2014;6(6):192-6.

21. Mridul M, Manjit C, Sibarani T. Concurrent infection of typhoid and dengue: A vice-versa study at Lakhimpur. Int J Curr Pharm Rev Res 2016;7(1):30-3.

22. Banerjee T, Shukla BN, Fiilgona J, Anupurba S, Sen MR. Trends of typhoid fever seropositivity over ten years in North India. Indian J Med Res 2014;140(2):310-3.

23. Feasey NA,Archer BN, Heyderman RS, Sooka A, Dennis B, Gordon MA, et al. Typhoid fever and invasive non-typhoid salmonellosis, Malawi and South Africa. Emerg Infect Dis 2010;16(9):1448-51.

24. Parry MC, Hoa NT, Diep TS, Wain J, Chinh NT, Vinh H, et al. Value of a single - Tube widal test in diagnosis of typhoid fever in Vietnam. J Clin Microbiol 1999;37(9):2882-6. 